\title{
Desafios e oportunidades do sistema informático
}

Maria José Ribas*

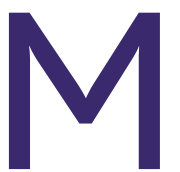

uito se tem dito sobre o papel dos computadores na nossa prática clínica. As opiniões são geralmente inflamadas, baseiam-se na nossa experiência e denotam o desgaste dos profissionais com as exigências que estes meios trazem a uma especialidade muito complexa. Este editorial é uma reflexão pessoal sobre os desafios e oportunidades que nos colocam.

Aviso: gosto de usar computadores, gadgets, aplicações e afins, acredito que não têm nada contra mim, não deixo que me irritem, não acredito que tenham sentimentos e, por isso, não acordam de manhã para me infernizar a vida. Não deixo que interfiram com o bem-estar dos meus doentes, defendo o seu uso como ferramentas ao meu serviço e dos utentes e não o contrário. Acredito que tenho o direito de ser feliz no trabalho, que posso fazer alguma coisa para melhorar os problemas e, por último, que há coisas mais importantes na vida.

Há 15 anos atrás, a nossa vida era um inferno de papel. Era virtualmente impossível saber com rigor que patologias prevaleciam na comunidade, que medicamentos prescrevíamos, que diagnósticos fazíamos e apenas os obsessivos entre nós tinham uma pálida ideia das características da sua lista.

Atualmente, entre aplicações de uso diário e outras de uso menos frequente, contamos dezasseis, todas elas ligadas à prática clínica. Poucas estão integradas; a maioria não comunica entre si e exige abertura de novas janelas, introdução de novos logins e palavras-chave ou repetição de dados já registados noutro lado.

Devemos exigir que todas estas aplicações sejam integradas, evitando a sua multiplicação, e que tenham um mesmo aspeto ou interface para que a sua utilização seja intuitiva.

Hoje em dia baseamos decisões nacionais ou locais muito importantes nos nossos registos. Os registos são

* Médica de família. USF Garcia de Orta, Porto. um dever e são um direito. O direito que temos de mostrar que fazemos bem, de medir o nosso desempenho, de prestar contas aos nossos utentes. Nós, os responsáveis por esses registos, sabemos quão difícil é manter uma lista de problemas atualizada, colocar as datas do diagnóstico certas, retirar problemas que já passaram. E o que registamos é útil para o médico e para o doente na consulta seguinte? Quando usamos exclusivamente códigos da classificação internacional sabemos o que se passou naquela consulta? O que fazemos terá de facto impacto na saúde da população?

Devemos poder ter, de forma automática, fácil e em tempo real, os dados do nosso trabalho para tomar decisões sobre as necessidades da nossa população.

Deve tornar-se possível classificar problemas de forma automática, rever a permanência de determinados problemas na lista ou a data real do diagnóstico, dando lugar a informação fidedigna sobre a população.

A entrada do computador e dos registos informáticos na consulta veio também mudar a nossa forma de comunicar. Temos mais dificuldade em olhar os doentes nos olhos e percecionar os sinais não verbalizados. A nossa atenção deixou de estar totalmente centrada na pessoa, no diagnóstico e na decisão para se dividir por múltiplas tarefas não clínicas que nada têm a ver com medicina. Existe mais uma barreira física entre nós e chegamos a ocupar mais de $40 \%$ da nossa consulta em interação com o computador. ${ }^{1-2}$

Cada profissional chega a ter, no mínimo, dez nomes de utilizador diferentes, quatro palavras-passe. Com boa vontade, são-nos criados nomes imaginativos, mas sempre diferentes e nem todas as aplicações nos deixam mudar a palavra-passe.

Para começar a primeira consulta do dia conto sete cliques, para usar as diferentes aplicações chego a 17, são incontáveis os cliques por consulta, chegando uma consulta de saúde infantil a exigir 39 cliques. O tempo acumulado em esperas por rodinhas, ampulhetas e afins, quando acumulado, chega a minutos e, ao fim de 
um ano, acredito poder chegar a horas.

Devemos aumentar a capacidade dos servidores, atualizar as máquinas e garantir uma largura de banda que possibilite o trabalho de um modo otimizado e em tempo útil. Exige dinheiro, sim, mas compensa em eficiência e satisfação. Quem aceitaria ser operado com um bisturi ferrugento?

Devemos libertar o tempo dos profissionais de registos duplicados e triplicados, de transcrição de exames e documentos, de abertura de múltiplas janelas e aplicações, dos inúmeros cliques.

Os alertas, quando existem, são contraditórios, por vezes extensos, atrasados no tempo e pouco úteis para a segurança do doente. São frequentes as mensagens em pop-up, relacionadas com o processo informático em si e não com a clínica. Estas mensagens interrompem a comunicação e o ritmo da consulta e não têm relevância no diagnóstico, decisão ou tratamento do doente.

Devem ser introduzidos alertas de apoio à decisão e à prescrição, de risco de interações medicamentosas ou alergias, de internamento do doente, de existência de nova informação clínica disponível.

O sistema informático é o maior aliado da nossa memória. Permite um acesso mais rápido à informação do doente, que deve estar integrada e facilmente visível sem necessidade de abertura de novas aplicações, potenciar a comunicação entre prestadores de cuidados de saúde e facilitar a produção de informação relevante.

Devemos poder usar as especificidades da nossa especialidade que se perderam, como o genograma e alguns instrumentos de avaliação familiar, poder integrar fotografias, documentos e resultados analíticos de outras entidades no processo sem que os tenhamos de transcrever e lembretes para nós mesmos que nos ajudem a não cometer erros.

O computador deve ser uma ferramenta de diagnóstico, de apoio à decisão, de prevenção do erro e de capacitação do doente. O uso de imagem, vídeos, folhetos informativos, correio eletrónico, gráficos, calculadoras, eleva a nossa capacidade de informar o doente e tomar decisões em conjunto.

Devemos poder emitir pareceres, escrever cartas a colegas e informações clínicas sem ter de reescrever o que já está escrito ou, no limite, escrever em papel o que já foi registado em computador, em suma, desmateria- lizar tudo o possível para aumentar a eficiência e reduzir o erro.

Quando questionados sobre o seu trabalho, os profissionais usam termos como «desgaste», «tristeza», «corrida de obstáculos» e têm necessitado de muita resiliência e entrega.

Cerca de $75 \%$ das unidades de saúde familiar está insatisfeita ou muito insatisfeita com a largura de banda e com a interoperabilidade das aplicações informáticas e 55\% está insatisfeita ou muito insatisfeita com os seus computadores. $^{3}$

Podemos trabalhar horas sentados em posições incorretas. São vários os problemas de saúde ligados ao uso do computador, como as lesões por esforços repetidos, ${ }^{4-}$ ${ }^{5}$ alterações de visão, imobilidade, agravamento de doenças já existentes, ansiedade, irritabilidade e burnout.

Temos de prevenir já. Somos responsáveis, em primeiro lugar, pelo nosso bem-estar, sem o qual não podemos tomar decisões sérias sobre a vida de outras pessoas.

Os responsáveis hierárquicos devem investir tempo, energia e recursos no acompanhamento da saúde dos trabalhadores, na criação de condições físicas de trabalho, no apoio psicológico aos mais fragilizados.

Em conclusão, os sistemas informáticos e de informação devem ser concebidos e construídos para estar ao serviço dos doentes e dos profissionais, e não o inverso.

\section{REFERÊNCIAS BIBLIOGRÁFICAS}

1. Sobral D, Rosenbaum M, Figueiredo-Braga M. Computer use in primary care and patient-physician communication. Patient Educ Couns. 2015 Jul 8. [Epub ahead of print]. doi: 10.1016/j.pec.2015.07.002

2. Yaphe J. Computers and doctor-patient communication. Rev Port Med Geral Fam. 2013;29(3):148-9.

3. Associação Nacional das Unidades de Saúde Familiar. O momento actual da reforma dos cuidados de saúde primários em Portugal, 2014/2015: questionários aos coordenadores de USF [Internet]. Lisboa: USF-AN; 2015. Available from: http://www.usf-an.pt/index.php/emnoticia/299-estudo-momento-atual-2015

4. Edling C, Lindblom J, Skogholm M, Feychting M, Nordander C, Styf J, et al. Occupational exposures and neck and upper extremity disorders: a systematic review. Stockholm: Swedish Council on Health Technology Assessment; 2012. ISBN 9789185413485

5. Wahlström J. Ergonomics, musculoskeletal disorders and computer work. Occup Med. 2005;55(3):168-76.

ENDEREÇO PARA CORRESPONDÊNCIA

director@rpmgf.pt 